\section{Commentary: Learning from a King}

Keyan Mobli, MD, and Abe DeAnda, Jr, MD

Given the opportunity to review a manuscript written by an expert in the field, commentary is tempered in remembering the advice attributed to Ralph Waldo Emerson, "When you shoot a King, you must kill him." In this issue of JTCVS Techniques, Dr David ${ }^{1}$ has provided the readership a unique and extensive retrospective review of his series of patients undergoing aortic valve-sparing root replacement, an experience spanning 3 decades. As might be expected from the innovator of the procedure that bears his name, he has shown excellent short- and long-term outcomes in a diverse patient population, including patients with genomic disorders (eg, Marfan and LoeysDietz syndromes), patients with bicuspid aortic valves, and those with type A aortic dissections. Although other studies discuss the benefits of remodeling versus reimplantation, particularly in young patients with genetic disorders, ${ }^{2}$ the strength of this review lies in Dr David's eloquent description of the procedure as well as his discussion of his outcomes.

The evolution of the variations of the so-called David procedure reflect a thoughtful approach to a vexing problem, ie, how to preserve a functioning valve in the face of aortic root disease. Miller ${ }^{3}$ summarized 5 broad variations of the David procedure (Table 1). From a broad view, aortic valve remodeling and reimplantation for patients with aortic root aneurysms are techniques to decrease the discrepancy between the area of the aortic cusp and the aortic annulus, optimizing the amount of

\footnotetext{
From the Division of Cardiovascular and Thoracic Surgery, University of Texas Medical Branch-Galveston, Galveston, Tex.

Disclosures: The authors reported no conflicts of interest.

The Journal policy requires editors and reviewers to disclose conflicts of interest and to decline handling or reviewing manuscripts for which they may have a conflict of interest. The editors and reviewers of this article have no conflicts of interest.

Received for publication Dec 14, 2020; revisions received Dec 14, 2020; accepted for publication Dec 21, 2020; available ahead of print Dec 27, 2020.

Address for reprints: Abe DeAnda, Jr, MD, Division of Cardiovascular and Thoracic Surgery, University of Texas Medical Branch-Galveston, 301 University Blvd, Galveston, TX 77551 (E-mail: abdeanda@utmb.edu).

JTCVS Techniques 2021;7:81-2

2666-2507

Copyright (C) 2020 The Authors. Published by Elsevier Inc. on behalf of The American Association for Thoracic Surgery. This is an open access article under the CC BY-NCND license (http://creativecommons.org/licenses/by-nc-nd/4.0/).

https://doi.org/10.1016/j.xjtc.2020.12.033
}

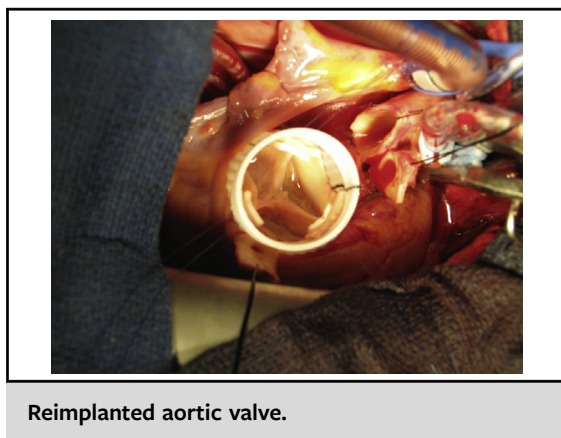

\section{CENTRAL MESSAGE \\ The development of the valve- sparing root replacement has had a positive impact on patient care with the caveat that great results require great technique.}

coaptation, while excising the abnormal aortic tissue. For success in any surgical procedure, understanding of the pathology, patient selection, and surgical technique must all be present. While briefly describing the pathology and the patient selection, the value of this review is in the depth of the explanation of the operative technique. This review highlights both surgical technique and clinical pearls that can only be developed over decades of practice.

The strength in the techniques described is the explanation of the rationale, as well as the potential pitfalls (and how best to avoid them) of the overall procedure. This includes a clear explanation of measurements of the cusp height and sinotubular junction diameter, and how the trileaflet aortic valve measurements differ from the bicuspid valve. These nuanced descriptions of the surgical technique are accompanied by detailed images outlining each step of the reimplantation.

The success of his surgical technique is in his outcomes. This may also reflect the potential weakness because such good outcomes are not just a matter of learning which graft and suture to use and where to put the stitches, but in the ability to see the real-time anatomy and make subtle but critical alterations in the procedure. We carry the twin desires to not only master the procedure but to teach it to the next generation of cardiovascular surgeons. Whether we can do justice to the David procedure and replicate his success remains to be seen, but it is indeed a worthy target for the next generation. 
TABLE 1. Miller classification of the David valve-sparing root replacement

\begin{tabular}{lll}
\hline Name & Classification & \multicolumn{1}{c}{ Description } \\
\hline David I & Reimplantation & Implantation of the aortic valve in a cylindrical tube graft \\
David II & Remodeling & Classic Yacoub \\
David III & Remodeling & David II combined with aortic annuloplasty \\
David IV & Reimplantation & David I with 4-mm larger graft and plication at the sinotubular junction \\
David V & Reimplantation & David I with 6- to 8-mm larger graft and plication at sinotubular junction and annulus to create pseudosinuses \\
\hline
\end{tabular}

Adapted from Miller. ${ }^{3}$

\section{References}

1. David TE. Reimplantation valve-sparing aortic root replacement is the most durable approach to facilitate aortic valve repair. J Thorac Cardiovasc Surg Tech. 2021;7:72-8.
2. David TE, Feindel CM, Webb GD, Colman JM, Armstrong S, Magnati M. Longterm results of aortic valve-sparing operations for aortic root aneurysm. J Thorac Cardiovasc Surg. 2006;132:347-54.

3. Miller DC. Valve-sparing aortic root replacement in patients with the Marfan syndrome. J Thorac Cardiovasc Surg. 2003;125:773-8. 